\title{
A reforma do Ensino Médio: uma ameaça à formação integrada?
}

\author{
The reform of High School: a threat to integrated training? \\ La reforma de la Enseñanza Secundaria: ¿una amenaza a la formación integrada?
}

Recebido: 20/01/2021 | Revisado: 23/01/2021 | Aceito: 25/01/2021 | Publicado: 01/02/2021

Francisco das Chagas Silva Souza
ORCID: https://orcid.org/0000-0002-9721-9812
E-mail: chagas.souza@ifrn.edu.br
Instituto Federal de Educação, Ciência e Tecnologia do Rio Grande do Nort, Brasil
José Gerardo Bastos da Costa Júnior
ORCID: https://orcid.org/0000-0002-8428-2281
E-mail: gerardo.junior@ifrn.edu.br
Francisca Leidiana de Souza
Instituto Federal de Educação, Ciência e Tecnologia do Rio Grande do Norte, Brasil
ORCID: https://orcid.org/0000-0002-8037-6539
Instituto Federal de Educação, Ciência e Tecnologia do Rio Grande do Norte, Brasil
E-mail: leidy_uerntour@htmail.com

\begin{abstract}
Resumo
O propósito deste artigo é refletir acerca dos desafios enfrentados pelo Ensino Médio Integrado diante da Reforma do Ensino Médio criada pela Lei no 13.415/2017. O Ensino Médio Integrado é compreendido pelos pesquisadores do campo Trabalho-Educação como a possibilidade de travessia para uma formação emancipatória dos sujeitos, superando assim a dualidade das políticas educacionais voltadas para a educação no Brasil. Trata-se de uma pesquisa bibliográfica cujas bases estão na produção acadêmica dos pesquisadores aludidos, além de publicações recentes acerca da Lei ${ }^{\circ}$ 13.415/2017. Os resultados apontam que essa Lei foi criada num cenário de ascensão da extrema direita, aprofundamento da política neoliberal e da mercantilização da educação no Brasil. Conclui-se que a Reforma do Ensino Médio, ao impor os Itinerários Formativos, reforça o dualismo, fragmenta os conhecimentos, hierarquiza as escolas e as disciplinas, e subordina a Educação Profissional às demandas do capital. Diante disso, consideramos que a tão propalada travessia para uma formação que integra trabalho, ciência, tecnologia e cultura corre o risco de retroceder diante dos interesses do capital e do enfraquecimento da democracia.
\end{abstract}

Palavras-chave: Lei no 13.415/2017; Ensino Médio Integrado; Educação Profissional; Ensino.

\begin{abstract}
The purpose of this article is to reflect on the challenges faced by Integrated High School in view of the High School Reform, created by Law No. 13,415/ 2017. Integrated High School is understood by researchers in the field of WorkEducation as a possibility of crossing towards a training that surpasses the educational duality in Brazil. This is a bibliographic research whose bases are in the academic production of the researchers referred to, in addition to recent publications about Law No. 13,415 / 2017. The results show that this Law was created in a scenario of the rise of the radical right-wing politics, the deepening of neoliberal politics and the commodification of education. It is concluded that the High School Reform, by imposing Formative Itineraries, reinforces dualism, fragments knowledge, hierarchizes schools and disciplines, and subordinates Professional Education to the demands of capital. In view of this, we consider that the so-called crossing to a formation that integrates work, science, technology and culture is in danger of falling back in the face of the interests of capital and the weakening of democracy.
\end{abstract}

Keywords: Law No. 13,415/ 2017; Integrated High School; Professional Education; Teaching.

\section{Resumen}

El propósito de este artículo es reflejar acerca de los desafíos enfrentados por la enseñanza secundaria integrada delante de la Reforma de la Enseñanza Secundaria creada por la ley n ${ }^{\circ}$ 13.415/2017. La Enseñanza Secundaria Integrada es comprendida por los investigadores del campo Trabajo-Educación como una posibilidad de travesía para una formación emancipadora de los sujetos, ultrapasando así la dualidad de las políticas educacionales dirigidas para la educación en Brasil. Se trata de una pesquisa bibliográfica cuyas las bases están en la producción académica de los investigadores aludidos, más allá de publicaciones recientes acerca de la ley n 13.415/2017. Los resultados apuntan que esa ley fue creada en un escenario de ascenso de la extrema derecha, profundización de la política neoliberal y de la mercantilización de la educación en Brasil. Se concluye que la reforma de la enseñanza secundaria, al imponer los Itinerarios Formativos, refuerza el dualismo, fragmenta los conocimientos, jerarquiza las escuelas y las disciplinas, y subordina la Educación Profesional a las demandas del capital. Delante de eso, consideramos que a tan cacareada travesía para una formación que integra trabajo, ciencia, tecnología y cultura corre el riesgo de retroceder delante de los intereses del capital y del debilitamiento de la democracia. 
Palabras clave: Ley n 13.415/2017; Enseñanza Secundaria Integrada; Educación Profesional; Enseñanza.

\section{Introdução}

O Ensino Médio Integrado (EMI) é apresentado, por pesquisadores do campo de estudo Trabalho-Educação, como uma alternativa para superar a dualidade na educação no Brasil. Mônica Ribeiro da Silva, por exemplo, enfatiza essa possibilidade ao intitular "Ensino Médio Integrado: travessias" em uma das obras que organizou (2013). Na apresentação, a autora compreende a forma integrada como um " [...] avanço em direção a uma formação mais qualificada na medida em que permitiria superar a justaposição e a dissociação entre ciência e trabalho, entre cultura e técnica, configurando percursos formativos mais orgânicos aos interesses e necessidades dos trabalhadores" (Silva, 2013, p. 8).

A palavra “travessia” também está presente em um artigo escrito por Maria Ciavatta e Marise Ramos (2011): “Ensino Médio e Educação Profissional o Brasil: dualidade e fragmentação”. As pesquisadoras dedicam a terceira parte do artigo para discutir sobre a integração do ensino como uma travessia acidentada. Acreditam que uma política consistente de profissionalização no ensino médio, “[...] condicionada à concepção de integração entre trabalho, ciência e cultura, pode ser a travessia para a organização da educação brasileira com base no projeto de escola unitária, tendo o trabalho como princípio educativo" (Ciavatta \& Ramos, 2011, p. 33, grifo nosso).

Do mesmo modo, Dante Henrique Moura (2013) em artigo intitulado "Ensino Médio Integrado: subsunção aos interesses do capital ou travessia para a formação humana integral?” dá realce à implicação dessa forma de oferta com a transição para um modelo de educação não comprometido com os ditames do capital.

Enfim, o EMI não se trata, conforme as autoras supracitadas, além de outros, de uma formação voltada exclusivamente para o trabalho, mas, sim, de um processo formativo que deverá incorporar e integrar, no ensino, aspectos científicos, tecnológicos, humanísticos e culturais, tendo o trabalho como princípio educativo. Com essa forma de articulação entre o Ensino Médio e o Profissional se processaria a travessia.

Considerando os posicionamentos desses estudiosos, com relação à perspectiva de superação da dualidade estrutural da educação brasileira, e diante do cenário recente de mudanças trazidas com a aprovação da Lei n ${ }^{\circ} 13.415$, de 16 de fevereiro de 2017, que reforma o Ensino Médio no Brasil, além de outras alterações na legislação propugnadas pelos governos dos presidentes Michel Temer (2016-2018) e Jair Bolsonaro (2019-), neste artigo refletimos acerca do "destino" que se aponta para a forma integrada ao Ensino Médio na Educação Profissional. Assim, questionamos: a propalada "travessia" corre riscos? Podemos crer ainda na redução da dualidade na educação brasileira num cenário político marcado pelo avanço da privatização, por propostas esdrúxulas como o "Escola sem Partido", a falácia da "ideologia de gênero" e outros patrulhamentos ideológicos que atentam contra a democracia e a inclusão no espaço escolar? É possível trabalhar numa perspectiva crítica e emancipatória, como propõe o EMI, sob o medo da "caça às bruxas" que a extrema direita vem empreendendo?

Obviamente, não temos como dar respostas para essas perguntas em face de sua atualidade no cenário político nacional. Contudo, podemos ponderar sobre esse tema, pondo-o em debate, visto que se trata de um processo em construção, o que nos leva, no máximo, a pensar nos possíveis rumos que o EMI poderá tomar.

Neste artigo, discutimos o caráter dual das políticas educacionais no Brasil voltadas para a Educação Profissional. Temos como amparo estudos dos pesquisadores do campo Trabalho-educação e artigos recentes publicados acerca da Reforma do Ensino Médio na segunda década do século XXI. Para isso, dividimos o texto em duas seções: na primeira, apresentamos um breve histórico da dualidade na educação, ao abordar como isso se fez e se faz presente nas políticas educacionais dos governos brasileiros no decorrer dos séculos XX e XXI. Em seguida, realizamos uma reflexão acerca dos desafios enfrentados pelo EMI diante do atual contexto de conservadorismo, aprofundamento da política neoliberal e da mercantilização da educação brasileira. 


\section{Metodologia}

Esta investigação se caracteriza como uma pesquisa bibliográfica, para a qual realizamos a busca, leitura, análise, discutimos os resultados obtidos em relação aos autores consultados nas referências (Pereira et. al., 2018). Para tanto, nos amparamos nos estudos dos pesquisadores do campo Trabalho-educação (Silva, 2013; Ciavatta \& Ramos, 2011; Moura, 2013; \& Saviani, 2007); em artigos recentes publicados acerca da Reforma do Ensino Médio na segunda década do século XXI (Hernandes, 2019; Gonçalves; 2017; \& Lino, 2017); e na análise de documentos oficiais do Ministério da Educação (Brasil, 2017; 2016; 1997).

\section{Da Dualidade à Integração: o EMI como Travessia}

Para Saviani (2007), trabalho e educação, a princípio, possuíam uma relação intrínseca. Amparado nos escritos de Karl Marx, Saviani realça que o homem é o único ser que possui a capacidade de trabalhar e de se educar a partir das experiências com os outros humanos ao agir sobre a natureza. Diferentemente dos animais irracionais - que se adaptam ao meio natural para garantir a sua sobrevivência -, o homem transforma e adapta a natureza às suas necessidades, embora também se ajuste a ela. Dessa maneira, para o autor, a essência do homem é o trabalho: "O que o homem é, é-o pelo trabalho. A essência do homem é um feito humano. É um trabalho que se desenvolve, se aprofunda e se complexifica ao longo do tempo: é um processo histórico" (Saviani, 2007, p. 154).

Ao se organizar, de forma coletiva no modo de produção comunal, os homens garantiam a sua sobrevivência, pois, ao mesmo tempo em que produziam, educavam-se. Logo, não havia uma separação entre o ato de produzir e o de educar, daí o trabalho ser percebido como princípio educativo. Contudo, com o desenvolvimento das forças produtivas, a sociedade, antes igualitária, dividiu-se em classes sociais: proprietários e não proprietários das terras. Aos primeiros, cabiam o trabalho intelectual e o controle e vigilância da produção; aos segundos, competia o produzir os meios de sobrevivência da sociedade (Saviani, 1989, 2003, 2007).

Nas condições em que as instruções eram dadas, a escola era algo acessível apenas aos homens livres, visto que a educação para os escravos era dada no próprio ato do trabalho forçado. Na medida em que a escola passou a ser o lugar destinado a uma pequena parcela da população, e o trabalho forçado à maioria, educação e trabalho já não mais possuíam a mesma relação de antes, pois este deixa de ser um princípio educativo e a educação passa a ser dual, visto que os seus objetivos variavam conforme as classes sociais (Saviani, 1989, 2003, 2007). Portanto, baseados nisso, podemos inferir que a dualidade na educação é anterior ao capitalismo, embora esse sistema a tenha aprofundado e naturalizado.

No caso do Brasil, historicamente, as políticas voltadas à educação reproduzem o divórcio entre a educação básica e o ensino de profissões. Apesar de essa característica estar presente, há séculos, para Ciavatta (2012), essa dualidade torna-se estrutural a partir da década de 1940, com a criação das Leis Orgânicas “[...] segmentando a educação de acordo com os setores produtivos e as profissões, e separando os que deveriam ter o ensino secundário e a formação propedêutica para a universidade e os que deveriam ter formação profissional para a produção" (Ciavatta, 2012, p. 87).

Para Moura (2007), a criação dos Decretos e Leis da Reforma Capanema, na década de 1940, visava dar suporte ao desenvolvimento da educação, tendo em vista que, ao tratar de forma especial a Educação Profissional, foram criadas leis específicas para esta em cada ramo da economia. O autor ressalta que a dualidade estava presente, haja vista que os conhecimentos necessários para o ingresso no ensino superior eram destinados somente à elite dirigente.

Nos anos de 1950, a realidade dual entre a formação básica e a profissional foi flexibilizada com as chamadas Leis de Equivalência, incluídas, em 1961, na primeira Lei de Diretrizes e Bases da Educação Nacional (Lei no 4.024/1961), estabelecendo, assim, a paridade entre o ensino básico, de nível médio, e o ensino técnico, permitindo aos concluintes do colegial técnico, a candidatura em qualquer curso de nível superior (Frigotto, Ciavatta \& Ramos, 2012). 
No final da década de 1960 e princípios dos anos de 1970, quando ocorreu o chamado "milagre econômico", a formação técnica assumiu um importante papel na educação brasileira. A abertura ao capital externo e a industrialização em expansão exigiam a ampliação do número de trabalhadores qualificados. Frigotto, Ciavatta e Ramos (2012) explicam que, com o aumento na demanda por empregos, os empregadores passaram a estabelecer critérios de exigências sobre o grau de escolaridade. É nesse contexto que se dá a criação da Lei n ${ }^{\circ} 5.692 / 1971$ e a consequente profissionalização compulsória do ensino de $2^{\circ}$ grau ${ }^{1}$.

Uma vez que o ensino técnico de nível médio favorecia o desenvolvimento da formação profissional em detrimento da formação geral, às classes populares restava a formação para o mercado de trabalho em expansão. Dessa maneira, a Lei $\mathrm{n}^{\circ}$ 5.692/1971, embora passasse a ideia do fim da dualidade, acentuava-a visto que para a classe trabalhadora era destinado o ensino profissionalizante, atendendo aos anseios do projeto desenvolvimentista (Frigotto, Ciavatta \& Ramos, 2012).

Nessa direção, Kuenzer (2009, p. 30) considera que, com a Lei no 5.692/1971,

Os historicamente excluídos desses benefícios, que se mantiveram na escola, não colheram frutos que pudessem permitir a superação da sua situação de classe, já que a "qualidade" dessa escola, que é a qualidade do propedêutico, do academicismo livresco, não lhes forneceu elementos para o necessário salto qualitativo, nem era essa a sua finalidade. Dessa forma, retorna-se ao modelo anterior a 1971: escolas propedêuticas para as elites e profissionalizantes para os trabalhadores; mantém-se, contudo, a equivalência.

O divórcio entre a formação geral e a profissional voltou ao debate quando da elaboração da nova Lei de Diretrizes e Bases da Educação Nacional, na década de 1990 (Lei nº 9.394/1996), momento em que foi travada uma luta entre setores progressistas e conservadores da educação. A tentativa de dar uma nova direção à educação brasileira, visando superar a dualidade estrutural, esteve na defesa da concepção de educação politécnica. Em termos epistemológicos e pedagógicos, esse ideário defendia um ensino que integrasse ciência e cultura, humanismo e tecnologia, visando o desenvolvimento de todas as potencialidades humanas. No entanto, essa concepção foi derrotada pela aprovação do Projeto de Lei apresentado pelo senador Darcy Ribeiro (Ramos, 2014).

No que diz respeito à Lei $\mathrm{n}^{\circ}$ 9.394/1996, Ramos (2010, p. 45, grifo da autora) afirma que “[...] o texto aprovado, na verdade, foi de uma lei minimalista, que permitiu uma onda de reformas na educação brasileira, dentre as quais esteve a realizada pelo Decreto n' 2.208/97”. Ademais, essa Lei, ao se estabelecer as diretrizes para a Educação Básica, reforçou a divisão entre a formação profissional e a geral, ao declarar, no artigo $5^{\circ}$, que “[...] a educação profissional de nível técnico terá organização curricular própria e independente do ensino médio, podendo ser oferecido de forma concomitante ou sequencial a este" (Brasil, 1996).

Portanto, ao longo do século XX, as políticas educacionais, em algumas situações, mantive velada a dualidade e, em outros, oficializaram-na. O Decreto n ${ }^{\circ}$ 2.208/1997, do presidente Fernando Henrique Cardoso, é um exemplo desse segundo aspecto. Conforme Frigotto (2010a, p. 32) “O Decreto 2.208/97 restabeleceu o dualismo entre educação geral e específica, humanista e técnica, destroçando, de forma autoritária, o pouco ensino médio integrado existente [...]”. Logo, para esse autor, “Inviabilizou-se, justamente e não por acaso, os espaços, [...] onde existiam as bases materiais de desenvolvimento da educação politécnica ou tecnológica" (Frigotto, 2010a, p. 32).

O Decreto n ${ }^{\circ}$ 2.208/1997 representou a vitória de educadores conservadores, da elite econômica brasileira e dos organismos internacionais que tinham interesses na formação imediata de mão de obra para o mercado, fato que se explicitou com a Portaria no 1005/1997 ao implementar o Programa de Reforma da Educação Profissional - PROEP (Brasil, 1997). O

\footnotetext{
${ }^{1}$ A compulsoriedade do ensino profissionalizante no $2^{\circ}$ grau sofreu críticas de vários setores da sociedade. Por causa disso, mas também da carência de recursos para a infraestrutura das escolas, essa obrigatoriedade foi extinta por meio da Lei $\mathrm{n}^{\circ}$ 7.044/1982, que tornou a oferta das habilitações profissionais uma opção dos estabelecimentos de ensino.
} 
PROEP visava criar um sistema de educação profissional separado do ensino médio, que habilitasse jovens e adultos " [...] para o mercado de trabalho mediante a oferta de cursos pós-médios não universitários e cursos livres de nível básico e de aperfeiçoamento, com o objetivo de obter uma oferta, dentro do país, de mão-de-obra melhor qualificada" (Programa de Reforma da Educação Profissional, 2006, p. 5).

Não é possível entendermos o referido Decreto sem considerarmos a introdução, cada vez mais acirrada, do ideário neoliberal e das influências dos organismos internacionais como o Banco Interamericano de Desenvolvimento (BID), o Banco Mundial (BM) e o Fundo Monetário Internacional (FMI), nas políticas educacionais no Brasil.

Conforme Torres (2009), o Banco Mundial, amparado no discurso de melhoria de qualidade da Educação Básica, apresenta um "pacote” de reforma para os países em desenvolvimento, apesar de cada um destes possuir especificidades. São, segundo a autora, propostas elaboradas basicamente por economistas dentro da lógica e da análise econômica. "A relação custobenefício e a taxa de retorno constituem as categorias centrais a partir das quais se define a tarefa educativa, as prioridades de investimento [...], os rendimentos, e a própria qualidade” (Torres, 2009, p. 138, grifos da autora). Há, portanto, uma superposição do econômico em detrimento do pedagógico:

Boa parte de quem opina hoje de quem opina hoje sobre o que tem ou não tem de ser feito em educação, tomando importantes decisões neste campo, tanto no âmbito local como mundial, carece do conhecimento e da experiência necessários para lidar com os campos sobre os quais se pronuncia e decide: a educação básica, o ensino e a aprendizagem em sala de aula, a aprendizagem infantil, a capacitação docente, o desenvolvimento e a reforma curricular, as políticas linguísticas, a aquisição da lecto-escrita, a elaboração de textos escolares e outros materiais instrucionais, a avaliação da aprendizagem etc. poucos deles estiveram alguma vez na frente de uma classe e de um grupo de alunos numa instituição escolar. Poucos mantêm seus filhos no sistema público para o qual são pensadas e supostamente desenhadas as propostas. A virtual ausência do professorado na definição, discussão e tomada de decisões de política educativa termina por selar esse discurso formulado por economistas para ser implementado por educadores (Torres, 2009, p. 139).

A formação rápida do trabalhador para atender às demandas do mercado, aliada à redução do papel do Estado deram a tônica nas políticas educacionais que empreenderam as reformas na educação na última década do século XX, como observam Martins (2000), Frigotto e Ciavatta (2006), Frigotto (2010a, 2010b), Shiroma, Moraes e Evangelista (2011), dentre outros estudiosos do assunto.

Em 2003, a equipe que assumiu o Ministério da Educação, quando da posse do presidente Luiz Inácio Lula da Silva, mostrou-se disponível para reformar as políticas para a Educação Profissional. Para tanto, foram resgatadas “[...] as contribuições acadêmicas geradas nas últimas décadas, as experiências institucionais e de grupos comunitários, explorando os espaços legislativos e corrigindo as distorções havidas durante esse percurso" (Ramos, 2014, p. 66). Assim, foi revogado o Decreto 2.208/1997, substituindo-o pelo Decreto n ${ }^{\circ}$ 5.154, em 23 de julho de 2004, o qual estabelece, em seu parágrafo primeiro, as três formas pelas quais se dará a articulação entre a Educação Profissional Técnica de Nível Médio e o Ensino Médio: a Integrada, a Concomitante e a Subsequente (Brasil, 2004). Frisamos que estas duas últimas já estavam previstas no Decreto $\mathrm{n}^{\circ} 2.208 / 1997$ e foram mantidas, gerando críticas ao governo Lula, visto que são consideradas como não geradoras da integração pretendida pelos educadores envolvidos nas discussões relatadas por Ramos (2014).

Apesar disso, para Moura (2007), a possibilidade de integração significou um avanço nas políticas para a Educação Profissional, pois, mesmo que não signifique a aplicação da educação tecnológica ou politécnica, uma bandeira de luta dos educadores do campo do trabalho-educação, a forma integrada volta-se para essa direção visto que, nela, estão presentes os princípios da construção de uma educação que une os eixos trabalho, ciência, tecnologia e cultura.

A lógica do ensino integral, conforme orienta Ciavatta (2012, p. 84), configura-se na articulação entre o trabalho como princípio educativo: 
O que é integrar? É tornar íntegro, tornar inteiro, o quê? A palavra toma o sentido moral em alguns usos correntes. Mas não é disto que se trata aqui. Remetemos o termo ao seu sentido de completude, de compreensão das partes no seu todo ou da unidade no diverso, de tratar a educação como uma totalidade social, isto é, nas múltiplas mediações históricas que concretizam os processos educativos. No caso da formação integrada ou do ensino médio integrado ao ensino técnico, queremos que a educação geral se torne parte inseparável da educação profissional em todos os campos onde se dá a preparação para o trabalho: seja nos processos produtivos, seja nos processos educativos como a formação inicial, como o ensino técnico, tecnológico ou superior.

Para Ciavatta (2012), a articulação entre trabalho e educação busca a superação da dualidade entre o trabalho manual e o intelectual, na união entre a cultura, a ciência e a tecnologia como partes em um todo, sendo esses princípios fundamentais para a organização do currículo integrado.

Conforme Frigotto, Ciavatta e Ramos (2012, p. 44), a proposta do EMI está voltada para a construção de uma educação alicerçada nos princípios da politecnia:

[...] a educação politécnica não é aquela que só é possível em outra realidade, mas uma concepção de educação que busca, a partir do desenvolvimento do capitalismo e de sua crítica, superar a proposta burguesa de educação que potencialize a transformação estrutural da realidade. O ensino médio integrado é aquele possível e necessário em uma realidade conjunturalmente desfavorável - em que os filhos dos trabalhadores precisam obter uma profissão ainda no nível médio, não podendo adiar este projeto para o nível superior de ensino -, mas que potencialize mudanças para, superando-se essa conjuntura, constituir-se em uma educação que contenha elementos de uma sociedade justa.

Ao contrário de uma formação dividida ou específica para uma determinada área, a formação omnilateral (ou onilateral) apresenta-se como um suporte para suprir diferentes necessidades. Desse modo, Manacorda (2007, p. 87), ao salientar a realidade da alienação humana, realça a "[...] exigência da omnilateralidade, de um desenvolvimento total, completo, multilateral, em todos os sentidos, das faculdades e das forças produtivas, das necessidades e da capacidade da sua satisfação".

Contrapondo-se à concepção de ensino incentivada pelo capital, na qual se objetiva fragmentar a formação de trabalhadores para atender aos requisitos de uma determinada área no mercado de trabalho, a formação omnilateral propõe que os aspectos manuais e intelectuais do processo de trabalho sejam indissociáveis. Logo, na medida em que executamos uma técnica manual, exercemos também uma ação intelectual (Saviani, 1989). Portanto, distintamente da educação tecnicista e unilateral, o Ensino Médio Integrado (EMI) se fundamenta numa concepção de currículo que agrega os conhecimentos técnicos, científicos, culturais e sociais, e procura ver o sujeito na sua completude.

Nessa direção, Ramos (2007, p. 3) apresenta dois pilares para esse modelo de educação: “[...] Um tipo de escola que não seja dual, ao contrário, seja unitária, garantindo a todos o direito ao conhecimento; e uma educação politécnica, que possibilita o acesso à cultura, a ciência, ao trabalho, por meio de uma educação básica e profissional”. Todavia, a autora adverte que politecnia não significa o ensino de muitas técnicas, mas “[...] uma educação que possibilita a compreensão dos princípios cientifico-tecnológicos e históricos da produção moderna, de modo a orientar os estudantes à realização de múltiplas escolhas" (Ramos, 2007, p. 3).

Ao contrário da ideia de polivalência, na qual o sujeito desempenha diversas habilidades sem que haja o crescimento intelectual e a evolução no processo de compreensão das partes em sua totalidade, a ideia de politecnia surge como uma maneira de integrar os conhecimentos que foram historicamente separados. Por assim conceber, Kuenzer (2009, p. 86) define politecnia como “[...] a superação de um conhecimento meramente empírico e de formação apenas técnica, através de formas de pensamento mais abstratas, de crítica, de criação, supondo autonomia”.

Logo, compreende-se que a formação politécnica vai além da simples soma de conhecimentos ao possibilitar ao jovem “[...] novas percepções que passam a configurar uma compreensão nova, e superior, da totalidade, que não estava dada no ponto 
de partida" (Kuenzer, 2009, p. 87). Nesse diapasão, Saviani (1989, p. 15) afirma que "O que a ideia da politecnia tenta introduzir é a compreensão desse fenômeno, a captação da contradição que marca a sociedade capitalista, e a direção de sua superação".

Além do trabalho como princípio educativo, da formação omnilateral e da politécnica, o EMI também está ancorado nos princípios da Escola Unitária, defendidos pelo filósofo italiano Antonio Gramsci. Para ele, considerando a realidade em que vivia na Itália, o sistema educacional estava em crise e, para superá-la, a solução seria uma “[...] escola única inicial de cultura geral, humanista, formativa, que equilibre de modo justo o desenvolvimento da capacidade de trabalhar manualmente (tecnicamente, industrialmente) e o desenvolvimento das capacidades de trabalho intelectual" (Gramsci, 2004, p. 33).

Essa escola também é "única" porque deve equilibrar a formação do estudante para os trabalhos manual e intelectual. Assim, conforme Martins (2000, p. 13), Gramsci admitia que a escola "[...] pode tornar-se um significativo instrumento de elevação do nível intelectual e moral das massas, uma das condições subjetivas para que o sujeito atue junto às condições objetivas de forma a viabilizar o processo revolucionário".

Contudo, apesar de concordar com a importância da escola unitária, Oliveira $(2009$, p. 147) questiona a possibilidade real da sua efetivação na sociedade capitalista. Sua descrença vem do fato de que "[...] o sistema capitalista, a cada nova fase do seu processo de desenvolvimento, cria um tipo de trabalhador coerente com o movimento de expropriação e de subordinação de si mesmo".

Consideramos a reflexão de Oliveira (2009) perfeitamente plausível, haja vista o atual contexto histórico e político da atualidade e as suas implicações nas políticas educativas são, em grande medida, conservadoras.

\section{A Lei $N^{\circ}$ 13.415/2017: Impasses e Ameaças à Integração}

Reconhecemos que, na prática, o EMI não é algo simples de ser posto executado. Alguns elementos explicam essa dificuldade: a ausência de formação contínua de professores para essa modalidade; o caráter disciplinar das propostas curriculares; o distanciamento entre as teorias pedagógicas e as práticas docentes; a insuficiência (ou inexistência) de uma preparação do futuro professor para a Educação Profissional nos currículos das universidades, sobretudo nos cursos de bacharelado, dentre outros aspectos. Por conseguinte, o exercício de práticas integradoras, quando ocorre, passa por uma reconstrução contínua, na qual os docentes aprendem a partir de erros e acertos ou com experiências desenvolvidas pelos seus pares.

Porém, na segunda década do século XXI, um novo elemento vem se somar aos elencados acima, colocando em riscos as bases epistemológicas do EMI ou mesmo a sua existência nos currículos das instituições de Educação Profissional: a Reforma do Ensino Médio promovida pela Lei no 13.415, sancionada pelo presidente Michel Temer em 16 de fevereiro de 2017.

Não podemos entender essa Lei senão associando-a a um conjunto de reformas de cunho neoliberal, colocado em prática nos governos dos presidentes Michel Temer e Jair Bolsonaro em atendimento aos interesses de agentes do capital nacional e estrangeiro. Podemos citar, como exemplos, a Emenda Constitucional n ${ }^{\circ}$ 95/2016, que estabeleceu um limite de investimentos do Estado por um período de 20 anos (2017-2036); a Lei $n^{\circ}$ 13.467/2017, que alterou a Consolidação das Leis do Trabalho (CLT); a aprovação da Emenda Constitucional n ${ }^{\circ}$ 103/2019, mudando o sistema de previdência social. Podemos ainda acrescentar a tentativa de aprovar o PL no 7.180/2014, conhecido como "Escola sem Partido", restringindo as liberdades de expressão e de pensamento no espaço escolar; e o lançamento, em 2019, dos programas "Novos Caminhos" e "Future-se".

Assim, Moura e Lima Filho (2017, p. 111) acreditam que a Lei no 13.415/2017:

[...] está abrigada por uma racionalidade maior, que alberga um conjunto de medidas, em curso ou em elaboração, cujo objetivo é reconfigurar o Estado brasileiro no sentido de torná-lo ainda "mais mínimo" no que se refere às garantias dos direitos sociais e "mais máximo" para regular os interesses do grande capital nacional e internacional, especialmente o financeiro/especulativo. Trata-se, assim, de uma nova fase de radicalização do neoliberalismo, que visa perpetrar um 
golpe contra a classe trabalhadora mais pobre do País, alcançada pelas políticas públicas inclusivas das duas primeiras décadas deste século.

Importa destacar que alguns problemas apontados em relação ao Ensino Médio em termos de qualidade, oferta, baixos índices nas avaliações externas, dentre outros, já estavam em discussão em anos anteriores à sanção da Lei n $13.415 / 2017$. Um exemplo disso foi a criação, em 2012, da Comissão Especial para Reformulação do Ensino Médio, composta por representantes do MEC, deputados federais, secretários de educação, gestores de centros de ensino, pesquisadores e representantes de entidades da área da educação.

No entanto, apesar dos debates que vinham ocorrendo, em 22 de setembro de 2016, o então presidente Michel Temer instituiu a reforma por meio da Medida Provisória no 746/2016, que veio a se tornar a Lei no 13.415/2017. Na Exposição de Motivos $n^{\circ}$ 84/2016, o ministro da educação à época, José Mendonça Bezerra Filho, justificou a alteração da LDB. Para ele: “Atualmente o ensino médio possui um currículo extenso, superficial e fragmentado, que não dialoga com a juventude, com o setor produtivo, tampouco com as demandas do século XXI” (Brasil, 2016). Adiante, destaca que os jovens "[...] são forçados a cursar, no mínimo, treze disciplinas obrigatórias que não são alinhadas ao mundo do trabalho [...]” (Brasil, 2016). Baseado em tais argumentos, para o ministro, o novo modelo de Ensino Médio oferecerá também cursos de qualificação, estágio e ensino técnico conforme as disponibilidades de cada sistema de ensino, "o que alinha as premissas da presente proposta às recomendações do Banco Mundial e do Fundo das Nações Unidas para Infância - Unicef' (Brasil, 2016, grifo nosso).

Percebe-se claramente a preocupação do MEC em alinhar as políticas educacionais brasileiras às orientações dos organismos internacionais, fato recorrente na proposição e implementação de políticas públicas no Brasil e na América Latina na segunda metade do século XX, sobretudo para a educação de primeiro grau, em virtude da Conferência Mundial sobre Educação para Todos, realizada em Jomtien, em 1990, convocada conjuntamente pela UNESCO, UNICEF, PNUD e o BM (Torres, 2009).

A Lei $n^{\circ} 13.415 / 2017$ promoveu profundas mudanças na LDB: alterou os artigos 24, 26, 36, 44, 61 , 62 e introduziu o artigo 35-A, estabelecendo que a Base Nacional Curricular Comum (BNCC) definirá direitos e objetivos de aprendizagem do Ensino Médio, conforme diretrizes do Conselho Nacional de Educação (CNE), por áreas do conhecimento. Modificou ainda o artigo 318 da CLT, o artigo 16 do Decreto-Lei n $236 / 1967$, revogou a lei que tornava obrigatório o ensino de Língua Espanhola e instituiu uma política de fomento ao Ensino Médio em tempo integral.

Quanto à organização curricular, o artigo $4^{\circ}$ da Lei n ${ }^{\circ}$ 13.415/2017 alterou o artigo 36 da LDB ao estabelecer que:

O currículo do ensino médio será composto pela Base Nacional Comum Curricular e por itinerários formativos, que deverão ser organizados por meio da oferta de diferentes arranjos curriculares, conforme a relevância para o contexto local e a possibilidade dos sistemas de ensino, a saber cinco itinerários formativos:

I - Linguagens e suas Tecnologias;

II - Matemática e suas Tecnologias;

III - Ciências da Natureza e suas Tecnologias;

IV - Ciências Humanas e Sociais Aplicadas;

V - Formação Técnica e Profissional. (Brasil, 2017, grifo nosso).

Vistos em uma perspectiva crítica, os itinerários formativos não só oficializaram a fragmentação do conhecimento, confrontando-se com os princípios da interdisciplinaridade, mas também geraram a falácia de que os estudantes terão opções de escolher qual deles quer seguir. Ora, parece óbvio que as escolas privadas deverão ofertar um Ensino Médio mais consistente e diverso, enquanto as escolas públicas estarão desobrigadas de cumprir o máximo, pois a lei realça que as ofertas desses itinerários se darão de acordo com a "possibilidade dos sistemas de ensino". Certamente, isso reforçará a dualidade e a segregação educacionais como analisa Gonçalves (2017, p. 141): 
[...] a reforma criará um grande abismo entre as instituições públicas e privadas, aumentado de modo bastante grave as desigualdades sociais e culturais no País. As redes privadas que já competem divulgando seu desempenho no Enem e publicizando que ensinam mais que outras escolas não perderão a oportunidade de organizar currículos bastante sólidos para seu público, enquanto os estudantes das escolas públicas estaduais terão que se contentar com a ênfase que o sistema de ensino julgar possível ser ofertada.

Também Hernandes (2019) pondera acerca da hierarquização entre as escolas. Para ele, aquelas com mais recursos, sobretudo as particulares, poderão oferecer os conteúdos que constituem a base para o acesso ao Ensino Superior, além dos conteúdos básicos para a permanência dos estudantes nessa modalidade de ensino; “as escolas 'remediadas' poderão compor e organizar quais e quantos arranjos curriculares puderem [...]” (Hernandes, 2019, p. 7); já as escolas mais pobres poderão oferecer arranjos mais pobres, que não demandem recursos.

Não por acaso, para organizar a Reforma do Ensino Médio os interlocutores do MEC não foram universidades, pesquisadores, professores e estudantes, mas empresários participantes de organizações como o Instituto Alfa Beta, Sistema S, Instituto Unibanco, Instituto Ayrton Senna, Fundação Itaú, entre outros (Gonçalves, 2017). Ou seja, a Reforma se tornou um negócio promissor para os grupos empresariais, fato que pode ser atestado pelos empréstimos feitos aos bancos internacionais para a sua implementação. Um exemplo disso é a manchete do Portal Globo (G1) “MEC poderá pedir empréstimo de até R\$ 800 milhões para financiar reforma do ensino médio", publicada em 18 de julho de 2017. O recurso era proveniente do Banco Internacional para Reconstrução e Desenvolvimento (Bird) e 90\% desse valor "deverá ser usado pelo MEC para apoiar as secretarias estaduais de Educação na implantação do novo ensino médio" e o restante do financiamento, segundo a pasta, será usado em "serviços de consultoria especializados, de alto nível, para apoiar o MEC e as secretarias estaduais e distrital” (MEC.... 2017).

Também é preciso observar que o currículo definido pela BNCC hierarquiza as áreas do conhecimento ao estabelecer disciplinas obrigatórias, pressupondo que alguns conhecimentos são mais importantes que outros. É o caso das disciplinas Língua Portuguesa e Matemática, nos três anos do Ensino Médio, estabelecido no parágrafo $3^{\circ}$ do artigo $3^{\circ}$ da Lei 13.415/2017; e Língua Inglesa, em algum momento do curso, de acordo com o parágrafo $4^{\circ}$ do mesmo artigo (Hernandes, 2019).

Ainda merecem ponderação os parágrafos $6^{\circ}$ e $9^{\circ}$ do artigo $4^{\circ}$ da Lei $n^{\circ} 13.415 / 2017$, por permitirem a expedição de certificados intermediários para estudantes antes de estes finalizarem o Ensino Médio. O argumento é que, assim, eles podem se inserir de imediato no mercado de trabalho. Logo, "Sai de cena a escola como locus de formação do aluno, entram o setor produtivo ou os ambientes de simulação. Não mais os conhecimentos sistematizados serão ensinados, mas as vivências práticas de trabalho" (Hernandes, 2019, p. 8). Esse aligeiramento na formação dos discentes serve à lógica da empregabilidade, podendo se tornar um mero treinamento para a inserção no mercado de trabalho, principalmente para os discentes de baixa renda, empobrecendo a compreensão sobre a complexidade do mundo do trabalho que o EMI possibilita ao articular trabalho, cultura, ciência e tecnologia.

Outra polêmica introduzida pela Reforma é que, para determinadas disciplinas do Itinerário Formativo V (Formação técnica e profissional), é possível contratar professores com "notório saber", dispensando a formação superior. Conforme discutem Santos et al. (2020), tal alternativa trará uma precarização do trabalho docente, além de comprometer a qualidade do ensino na EP. Corroborando com tais inquietações, para Barcellos et al. (2017, p. 132), a Reforma do Ensino Médio poderá “abrir precedentes para a contratação de profissionais não licenciados para atuarem em outras modalidades de ensino pelo critério de notório saber”. Dessa forma, essa permissão da Lei n 13.417/2017 abre uma lacuna perigosa no sentido de incentivar ainda mais a desvalorização dos profissionais da educação, visto que desprestigia o essencial processo de formação docente para a construção de referenciais teóricos e práticos no ofício de ensinar e aprender no "chão" da sala de aula.

Face ao exposto, voltamos ao nosso questionamento inicial: a Lei 13.415/2017 põe em risco a consolidação e a permanência do EMI? 
Embora o EMI esteja em crescimento no cenário educacional brasileiro², não podemos ouvidar que os contextos histórico e político da segunda década do século XXI ameaçam iniciativas que se contraponham à ascensão dos grupos de extrema direita no Brasil e em vários países do mundo. Para Löwy (2015, p. 657), o crescimento da extrema-direita na Europa se dá em função do aprofundamento da globalização capitalista neoliberal, a crise econômica que esse continente vem sofrendo desde 2008, além de “[...] uma longa tradição antissemita espalhada em certos países; a persistência daquelas correntes que colaboraram durante a Segunda Guerra Mundial; e a cultura colonial que impregna atitudes e comportamentos mesmo muito tempo depois da descolonização".

No que diz respeito ao Brasil, vê-se, desde 2010, um crescimento da direita. Codato, Berlatto e Bolognesi (2018, p. 870), ao estudaram o perfil dos políticos de direita do Brasil, consideram que a atual direita esta não é a habitual. "Ao lado daquela direita ligada aos grandes partidos vinculados historicamente ao regime ditatorial-militar há novos tipos de partidos e novos perfis de políticos nesse lado do espectro político". Messemberg (2017) e Silva (2017) também fazem referência a "nova" direita que "emergiu" e se fortaleceu nessa segunda década do século XXI e "saiu do armário" utilizando a mídia e as redes sociais.

Silva (2017, p. 172) explica a "vergonha” que a direita tinha de si própria:

[...] no Brasil não havia, até muito recentemente, uma identificação pública com a direita por parte da população em geral. Ser de direita está associado a uma condição de classe, e, portanto, os donos do capital nem sempre fazem questão de mostrar sua opulência. Não era algo que se desejava alardear, e sim conservar. Muitos podem ter se sentido constrangidos com os longos anos de Ditadura no Brasil, tornando difícil a sustentação da defesa pública de políticas de direita, embora no âmbito privado essa defesa nunca tenha desaparecido. Mas, os mesmo que se calaram publicamente sobre as mazelas da ditadura brasileira, não se cansaram, a partir dos anos 1990, de atacar o comunismo ou o socialismo como sendo ditaduras. Portanto, não é que não houvesse um centro de pensamento de direita, pelo contrário, ele nunca deixou de existir e se complexificou, se capilarizou ao longo dos últimos anos.

Além das posições ideológicas de esquerda presentes no interior do EMI, a travessia que essa oferta possibilita ao propor o fim da dualidade também sofre riscos uma vez que a Reforma do Ensino Médio aqui mencionada aponta para uma concepção diversa da formação humana integral. Os Itinerários Formativos são exemplos disso na opinião de Moura e Lima Filho (2017, p. 124):

[...] o estabelecimento do itinerário formativo denominado "formação técnica e profissional" revela forte retomada da categoria dualidade estrutural, que historicamente tem se manifestado na educação nacional, como reflexo de uma sociedade cindida em classes, que destina aos trabalhadores mais empobrecidos processos educacionais pobres, caracterizados pela redução e instrumentalidade de conteúdos direcionados para aspectos meramente do fazer, em detrimento dos conhecimentos de base científico-tecnológica e sócio histórica.

Apesar da Lei 13.415/2017 (Brasil, 2017) possibilitar a manutenção da Educação Profissional Técnica de Nível Médio (EPTNM) nas escolas, Costa e Coutinho (2018) questionam se haverá verbas para a manutenção e expansão de cursos que tenham o currículo integrado com a formação geral, se serão realizados concursos para professores da carreira de educação básica, técnica e tecnológica (EBTT), e quais os limites da autonomia institucional serão mantidos sem danos aos projetos institucionais que vão de encontro às políticas governamentais.

Gonçalves (2017, p. 139) também elenca uma série de questionamentos quanto à escolha do MEC de indicar a formação técnica e profissional como uma das ênfases:

${ }^{2}$ Conforme o Censo da Educação Básica 2019, o número de matrículas na forma integrada subiu de 485.685 mil, em 2015 , para 623.178 mil, em 2019 (Instituto Nacional de Estudos e Pesquisas Educacionais Anísio Teixeira, 2020, p. 9). 
Quais são as reais condições das escolas públicas estaduais para oferecer esse itinerário? A maioria das escolas públicas estaduais brasileiras não possui condições materiais e de infraestrutura, nem disponibilidade de profissionais para dar conta dessa ênfase. Aproveitando-se dessas condições, o governo abriu a possibilidade de parcerias com o setor privado para a oferta do itinerário V e alterou a Lei n. 11.494/2007, que regulamenta o Fundo de Manutenção e Desenvolvimento da Educação Básica e de Valorização dos Profissionais da Educação. Não é à toa que o Sistema S está comemorando a Reforma do Ensino Médio [...].

Os rebatimentos e a insegurança fazem parte do cotidiano das instituições públicas que ofertam a EP. Exemplo disso foi a apresentação, pelo Executivo Federal, do PL n ${ }^{\circ}$ 11.279/2019, propondo a alteração da lei de criação dos Institutos Federais (Lei no 11.892/2008). As reações do Conselho Nacional das Instituições da Rede Federal de Educação Profissional, Científica e Tecnológica (CONIF) e de outras instituições levaram o autor do PL a retirá-lo da pauta de votação da Câmara dos Deputados, temporariamente, para possíveis ajustes.

Outro aspecto que merece ser destacado é o artigo 13 da Lei ${ }^{\circ}$ 13.45/2017 o qual apresenta uma confusão conceitual entre educação em tempo integral e educação integrada. Para Silva e Boutin (2018, p. 525) a educação em tempo integral “[...] visa muito mais a necessidade de ampliar o tempo do que de ampliar as possibilidades educativas comprometidas com a formação mais completa do educando, demonstrando que o que se deseja é, na verdade, um aluno por mais tempo na escola".

Face ao exposto, tudo leva a crer que o esforço teórico dos pesquisadores do campo trabalho-educação encontra hoje na Lei $n^{\circ} 13.415 / 2017$ e na fragmentação do conhecimento por meio dos itinerários formativos, fortes barreiras para a prática um ensino que supere a concepção de formação profissional apenas como um simples treinamento para atividades manuais, ao invés de conceber a educação como formação humana, como um processo de ampliação do conhecimento e da leitura do mundo (Ciavatta, 2019).

\section{Considerações Finais}

Este artigo foi escrito num cenário de retrocessos nas políticas educacionais e avanços da extrema direita no Brasil e no mundo, um cenário nada animador marcado pelo retorno de ideias há séculos superadas, redução de direitos sociais, limites à democracia, restrições às liberdades de expressão e de pensamento. Nas escolas, o receio "anda nas cabeças e nas bocas", como diz a famosa composição de Chico Buarque. A vigilância sob o trabalho dos professores e as ameaças de punições geram temores vencidos pelo processo de redemocratização. A sala de aula, aos poucos, vem deixando de ser lugar seguro para a expressão de ideias, de mobilizações e de conscientização.

A questão colocada no título deste artigo alude o risco de retrocedermos a uma Educação Profissional cujo foco é o mercado de trabalho e as demandas do capital. É sabido que esse tipo de formação não é novo e parece ser o correto para grande parcela da sociedade, mas compartilhamos a defesa de uma Educação Profissional comprometida com a formação humana "[...] entendida e praticada em relação aos conceitos de totalidade da vida social e do trabalho como atividade estruturante da vida humana em todo seu potencial, dignidade e ética" (Ciavatta, 2019, p. 145).

Dessa forma, concordamos com pesquisadores que veem a atual Reforma do Ensino Médio como um retorno aos anos 1940, com a Reforma Capanema, aos anos 1970, com a Lei 5.692/1971, e aos anos 1990, com o Decreto ${ }^{\circ}$ 2.208/1997. A Lei ${ }^{\circ}$ 13.415/2017 reforça dualismos educacionais, fragmenta a formação integral, hierarquiza escolas e disciplinas, sugere o ensino profissional para os mais pobres, subordina a Educação Profissional às demandas do capital.

Os itinerários formativos não só oficializam a flexibilização e a fragmentação do conhecimento, confrontando-se com os princípios da interdisciplinaridade, como também geram a falácia de que os estudantes terão opções de escolher qual dos cinco itinerários seguir, como se todas as escolas estivessem preparadas para oferta-los. No tocante ao Itinerário Formativo $\mathrm{V}$ (Formação Técnica e Profissional), a Reforma se aproxima mais da formação polivalente que da politecnia, uma das bandeiras de luta dos educadores progressistas. Nesse sentido, não é preciso um aluno politizado e questionador. Basta-lhe saber manipular 
Research, Society and Development, v. 10, n. 2, e0310212216, 2021

(CC BY 4.0) | ISSN 2525-3409 | DOI: http://dx.doi.org/10.33448/rsd-v10i2.12216

as máquinas conforme aprendeu com professores sem formação adequada mas que tiveram sua competência atestada como "notório saber".

Diante do exposto, sofre riscos a oferta de Educação Profissional que se apresenta como uma travessia para a superação do modelo de educação dualista que tivemos até então; uma proposta que permite àqueles que vivem do trabalho, um ensino que integra as esferas intelectual e laboral e proporciona, aos educandos, uma formação pautada nos princípios da omnilateralidade e da politecnia. Nessa perspectiva, não seria somente o aprendizado para uma função específica (a inserção no mercado), mas, sim, para o conhecimento crítico, reflexivo e emancipatório. Este artigo é apenas um ensaio reflexivo para contribuir com a discussão. Esperamos que outros pesquisadores possam também se aprofundar nesse debate que é atual e necessário diante de um cenário de incertezas.

\section{Referências}

Barcellos, M. E., Souza, E. G. de., Fontana, L. R., Toledo, S. W., \& Braga Júnior, C. (2017). A reforma do ensino médio e as desigualdades no Brasil. Revista Brasileira da Educação Profissional e Tecnológica, 2(13), 118-136. https://doi.org/10.15628/rbept.2017.6127

Brasil (2017). Presidência da República. Lei $n^{\circ} 13.415$, de 16 de fevereiro de 2017. Altera as Leis $\mathrm{n}^{\circ} 9.394$, de 20 de dezembro de 1996 , que estabelece as diretrizes e bases da educação nacional, e 11.494, de 20 de junho 2007, que regulamenta o Fundo de Manutenção e Desenvolvimento da Educação Básica e de Valorização dos Profissionais da Educação, a Consolidação das Leis do Trabalho - CLT, aprovada pelo Decreto-Lei no 5.452, de $1^{\circ}$ de maio de 1943 , e o DecretoLei no 236, de 28 de fevereiro de 1967; revoga a Lei no 11.161, de 5 de agosto de 2005; e institui a Política de Fomento à Implement ação de Escolas de Ensino Médio em Tempo Integral. (Conversão da Medida Provisória n ${ }^{\circ}$ 746, de 2016). Brasília, DF, 2017. http://www.planalto.gov.br/ccivil_03/_ato20152018/2017/lei/L13415.htm.

Brasil (2016). Ministério da Educação. Exposição de Motivos no 00084/2016/MEC. Brasília, DF, 2016. http://www.planalto.gov.br/ccivil_03/_Ato20152018/2016/Exm/Exm-MP-746-16.pdf.

Brasil (1997). Ministro de Estado da Educação e do Desporto. Portaria MEC $n^{\circ}$ 1005/97, de 10 de setembro de 1997. Implementa o Programa de Reforma da Educação Profissional - PROEP. Brasília, DF, 1997. http://portal.mec.gov.br/setec/arquivos/pdf/PMEC1005_97.pdf.

Ciavatta, M. (2012). A formação integrada: a escola e o trabalho como lugares de memória e de identidade. In G. Frigotto, M. Ciavatta, \& M. Ramos (Org.), Ensino Médio Integrado: concepções e contradições (pp. 83-106). Cortez.

Ciavatta, M. (2019) Trabalho-educação: uma unidade epistemológica, histórica e educacional. Trabalho Necessário, 17(32), 132-149. https://doi.org/10.22409/tn.17i32.p28306

Ciavatta, M. \& Ramos, M. (2011). Ensino Médio e Educação Profissional no Brasil: dualidade e fragmentação. Revista Retratos da Escola, 5(8), 27-41. https://doi.org/10.22420/rde.v5i8.45

Codato, A., Berlatto, F., \& Bolognesi, B. (2018). Tipologia dos políticos de direita no Brasil: uma classificação empírica, Análise Social, 4(229), 870-897. https://doi.org/10.31447/AS00032573.2018229.02

Costa, M. A., \& Coutinho, E. H. L. (2018). Educação Profissional e a Reforma do Ensino Médio: Lei no 13.415/2017, Educação \& Realidade, 43(4), 1633-1652. https://doi.org/10.1590/2175-623676506

Frigotto, G., Ciavatta, M., \& Ramos, M. (2012). A gênese do Decreto n. 5.154/2004: um debate no contexto controverso da democracia restrita. In G., Frigotto, M. Ciavatta, \& M. Ramos (Org.). Ensino Médio Integrado: concepções e contradições (pp. 21-56). Cortez.

Frigotto, G. (2010a). A relação da educação profissional e tecnológica com a universalização da educação básica. In J. Moll, A. Z. Kuenzer, A. F. B. Andrade, B. Kipnis, C. A. Simões, C. A. Koller, D. H. Moura, \& D. M. Lima Filho (Org.). Educação profissional e tecnológica no Brasil contemporâneo: desafios, tensões e possibilidade (pp. 25-41). Artmed.

Frigotto, G. (2010b). A produtividade da escola improdutiva: um (re)exame das relações entre educação e estrutura econômico-social capitalista. Cortez. Gonçalves, S. R. V. (2017). Interesses mercadológicos e o "novo" ensino médio. Revista Retratos da Escola, 11(20), 131-145. https://doi.org/10.22420/rde.v11i20.753

Gramsci, A. (2014). Caderno 12. In A. Gramsci. Cadernos do Cárcere, 2. (4a ed.). Civilização Brasileira.

Hernandes, P. R. (2019). A reforma do Ensino Médio e a produção de desigualdades na educação escolar. Educação, 44, 1-22. https://doi.org/10.5902/1984644434731

Instituto Nacional de Estudos e Pesquisas Educacionais Anísio Teixeira (2020). Censo da Educação Básica 2019: notas estatísticas. http://portal.inep.gov.br/informacao-da-publicacao/-/asset_publisher/6JYIsGMAMkW1/document/id/6798882.

Kuenzer, A. Z. (2009). Primeira Parte. In A. Z. Kuenzer (Org.) Ensino Médio: construindo uma proposta para os que vivem do trabalho (pp. 25-90.). Cortez.

Löwy, M. (2015). Conservadorismo e extrema-direita na Europa e no Brasil. Serviço Social \& Sociedade, 124, 652-664. https://doi.org/10.1590/0101-6628.044

Lino, L. A. (2017). As ameaças da reforma: desqualificação e exclusão. Revista Retratos da Escola, 11(20), 75-90. https://doi.org/10.22420/rde.v11i20.756 
Research, Society and Development, v. 10, n. 2, e0310212216, 2021

(CC BY 4.0) | ISSN 2525-3409 | DOI: http://dx.doi.org/10.33448/rsd-v10i2.12216

Manacorda, M. A. (2007). Marx e a pedagogia moderna. Alínea.

Martins, M. F. (2000). Ensino técnico e globalização: cidadania ou submissão? Autores Associados.

MEC poderá pedir empréstimo de até R\$ 800 milhões para financiar reforma do ensino médio. G1, Educação, https://g1.globo.com/educacao/noticia/mecpodera-pedir-emprestimo-de-ate-r-800-milhoes-para-financiar-reforma-do-ensino-medio.ghtml.

Messenberg, D. (2017) A direita que saiu do armário: a cosmovisão dos formadores de opinião dos manifestantes de direita brasileiros. Revista Sociedade e Estado, 32(3), 621-647. https://doi.org/10.1590/s0102-69922017.3203004

Moura, D. H. (2013) Ensino médio integrado: subsunção aos interesses do capital ou travessia para a formação humana integral? Educação e Pesquisa, 39, 705720. http://dx.doi.org/10.1590/S1517-97022013000300010

Moura, D. H. (2007) Educação básica e educação profissional e tecnológica: dualidade histórica e perspectivas de integração. Holos, 2(23), 4-30. https://doi.org/10.15628/holos.2007.11

Moura, D. H., \& Lima Filho, D. L. (2017) A reforma do ensino médio: regressão de direitos sociais. Revista Retratos da Escola, 11(20), 109-129. https://doi.org/10.22420/rde.v11i20.760

Oliveira, R. (2009) A possibilidade da escola unitária na sociedade capitalista. Cadernos de Educação, 32, 141-160. https://doi.org/10.15210/caduc.v0i32.1684

Pereira, A. S., Shitsuka, D. M., Parreira, F. J., \& Shitsuka, R. (2018). Metodologia da pesquisa científica. UFSM/NTE. https://repositorio.ufsm.br/bitstream/handle/1/15824/Lic_Computacao_Metodologia-Pesquisa-Cientifica.pdf?sequence=1

Ponciano, J. K., Castange, R. D., Lima, M. R. C., \& Lima, J. M. de. (2019). A “Base Nacional Comum Curricular” e a Lei n 13.415/2017: educação dos jovens brasileiros de volta aos "anos de chumbo". Educação, 44, 1-22. http://dx.doi.org/10.5902/1984644435824

Programa de Reforma da Educação Profissional. (2006) Regulamento Operativo II..ftp://ftp.fnde.gov.br/web/proep/regulamento_operativo_02_proep_2006.pdf

Ramos, M. (2010) Ensino médio integrado: ciência, trabalho e cultura na relação entre educação profissional e educação básica. In J. Moll, A. Z. Kuenzer, A. F. B. Andrade, B. Kipnis, C. A. Simões, C. A. Koller, D. H. Moura, \& D. M. Lima Filho (Org.). Educação profissional e tecnológica no Brasil contemporâneo: desafios, tensões e possibilidade (pp. 42-57). Artmed.

Ramos, M. (2007, 14 a 16 de agosto) Concepção de ensino médio integrado. [Palestra]. Seminário sobre ensino médio realizado pela Superintendência de Ensino Médio da Secretaria de Educação do Estado do Rio Grande do Norte. SEC/RN. forumeja.org.br/go/sites/forumeja.org.br.go/files/concepcao_do_ensino_medio_integrado5.pdf.

Ramos, M. (2014) História e política da educação profissional. Instituto Federal do Paraná.

Saviani, D. (2007) Trabalho e educação: fundamentos ontológicos e históricos. Revista Brasileira de Educação, 12(34), 152-180. https://doi.org/10.1590/S141324782007000100012

Saviani, D. (2003) O choque teórico da politecnia. Trabalho, Educação e Saúde, 1(1), 31-152. https://doi.org/10.1590/S1981-77462003000100010

Saviani, D. (1989) Sobre a concepção de politecnia. EPSJV/FIOCRUZ.

Shiroma, E. O., Moraes, M. C. M., \& Evangelista, O. (2011) Política educacional. (4a ed.). Lamparina.

Silva, M. R. (2013) Apresentação. In: M. R. SILVA (Org.). Ensino Médio Integrado: travessias. (7-11). Mercado das Letras.

Silva, M. R. (2018) A BNCC da reforma do ensino médio: o resgate de um empoeirado discurso. Educação em Revista, 34, 1-15. https://doi.org/10.1590/01024698214130

Silva, K. C. J. R., \& Boutin, A. C. (2018) Novo ensino médio e educação integral: contextos, conceitos e polêmicas sobre a re forma. Educação, 43(3), 521-534. https://doi.org/10.5902/1984644430458

Silva, C. L. S. (2017) Mídia e ascensão conservadora. Argumentum, 9(2), 172-182. https://doi.org/10.18315/argum..v9i2.15922

Santos, D. S., Cavalcante, R. P., Maldaner, J. J., \& Pereira Filho, A.D. (2020) O lugar da educação profissional e tecnológic a na reforma do ensino médio em contexto brasileiro: da Lei $\mathrm{n}^{\circ}$ 13.415/2017 à BNCC. Revista Brasileira da Educação Profissional e Tecnológica, 2, 114. https://doi.org/10.15628/rbept.2020.9488

Torres, R. M. (2009) Melhorar a qualidade da educação básica? As estratégias do Banco Mundial. In L. De Tommasi, M. J. Warde, \& S. Haddad (Org.). O Banco Mundial e as políticas públicas (6a ed.), 125-194. Cortez. 